\title{
Demonstration of a Technique to Construct a One-to-One Correspondence Between N and the Infinite Binary Decimals in $(0,1)$
}

\author{
Ron Ragusa ${ }^{1}$ \\ ${ }^{1}$ Affiliation not available
}

December 30, 2021

\section{Hosted file}

The Diagonalization Paradox 12-5-21.pdf available at https://authorea.com/users/266989/ articles/548452-demonstration-of-a-technique-to-construct-a-one-to-one-correspondencebetween-n-and-the-infinite-binary-decimals-in-0-1 